\title{
AGE-HARDENED NICKEL-BASE ALLOYS FOR ADVANCED ENERGY APPLICATIONS
}

\author{
John de Barbadillo, Brian Baker, Ronald Gollihue \\ Special Metals; 3200 Riverside Drive Huntington 25705, WV, USA \\ Keywords: Superalloys, Gamma Prime, Creep, Hot Corrosion, Welding, Manufacturing
}

\begin{abstract}
Alloy $740 \mathrm{H}$ was developed initially in the late 1990's for coal-fired boiler tubing for service at $700^{\circ} \mathrm{C}$ under the European Thermie project. In the ensuing years the opportunities for materials to serve in advanced power systems have expanded tremendously, posing many unique problems for designers, fabricators and alloy producers. Power plants have a design life of 40-years or more, are field erected by welding and must be periodically inspected and repaired. Many components such as hot transfer piping, valve bodies, turbine rotors and casings can be quite large. In addition to straight-wall tubes, plant construction requires tees (T) and wyes (Y), transitions, flanges, forged fittings and plate fabrications. Alloy $740 \mathrm{H}$ is a gamma prime strengthened alloy similar to alloy 263 , but optimized for creep strength, microstructure stability, hot corrosion resistance and heavy section weldability. This paper describes the processing, microstructure and properties required for age-hardenable nickel-base alloys for such advanced energy applications and this status for alloy $740 \mathrm{H}$ tube, pipe, fabrications and weld joints.
\end{abstract}

\section{Introduction}

The history of "superalloys" (defined in this paper as "age-hardened nickel-base alloys") is intimately connected to the development and evolution of the aircraft gas turbine engine. The superalloys were an enabling materials technology for the jet engine. The continuous drive for increased performance in turn drove new alloy and manufacturing technologies that form the basis of the industry of today. Gradually superalloys began to be adopted for other applications where the need for performance justified their inherently high cost compared to heat-resisting steels. Initial applications included diesel exhaust valves, high temperature springs, furnace hardware and metalworking dies. In the late 1970's the high strength and corrosion resistance of alloy 718 began to be exploited by the oil and gas industry for drill tools and later completion and safety tools and by the nuclear industry for springs and control rod guide mechanisms [1]. These applications require small to medium size parts, welds that can be made and homogenized in a shop environment and limited creep exposure.

A significant technological milestone was the development of alloy 706 for large frame gas turbine disks [2]. These disks were more than an order of magnitude larger in size than any aircraft disk in use at that time. In addition, the components were designed for a long life in semi-continuous operation under conditions where inspection is difficult. New methods of manufacturing and non-destructive testing were developed to prevent melt segregation and thermal stress cracking. Today thousands of these disks are in service in base-load and peaking applications in power plants around the world. This development leaves a legacy of technology for manufacturing large superalloy components for the power generation industry that serves as a basis for future advancement. 
The belief that carbon dioxide emissions must be controlled to combat global warming has spawned many new energy technologies including those seeking to make fossil-fired fuel plants more efficient. A seminal program was begun initially under the European collaborative COST Program to develop materials and technologies for coal fired boilers that could operate at $700^{\circ} \mathrm{C}$ and $35 \mathrm{MPa}$ steam pressure [3]. Such power plants are commonly called "Advanced-Ultra supercritical" (AUSC), a reference to the supercritical nature of the steam and the higher operating conditions compared with existing "Ultrasupercritical" plants. It was quickly realized that the "Creep Strength Enhanced Ferritic" steels were not suitable for use in the highest temperature parts of the boiler and turbine. Existing solid solution and age-hardened nickel-base alloys were evaluated and found to generally have characteristics suitable for power plant use. However, none of the alloys, in the forms and sizes then available, were ready for use. In the subsequent decades, the European program was greatly expanded and national collaborative programs were established in USA and Japan and then more recently in China, Korea, India and Russia.

Several existing alloys such as 617,263 and 282 have been modified to optimize certain attributes, while a number of entirely new alloys have been developed such as HR6W, USC 141, TOS1 SC 00 and 70 . These new alloys are strengthened by 1 - and many are designed for specific components in the boiler or turbine. There is currently a high level effort to develop production and fabrication technologies and to demonstrate their capability in controlled in-boiler test loops. The first demonstration plants are expected to be constructed in 2017-2020 time frame. Alloy $740 \mathrm{H}$ has been extensively tested in all of these programs and, through the efforts of the USA AUSC consortium, became the first age-hardened alloy to be approved by ASME for use in welded pressure boilers [4]. This alloy is the focus of the present paper because it has undergone the greatest degree of testing; however, the technology and observations are applicable to other alloys under consideration. The objective of this paper is to examine important criteria an age-hardenable alloy must attain for AUSC applications and where alloy $740 \mathrm{H}$ stands in this regard. The following discussion is organized to address the associated fundamental questions: 1) Does the alloy meet the AUSC concept goals? 2) Is the alloy microstructure stable for the design life of a commercial power plant? 3) Can the alloy be made in the component sizes and configurations required? 4) Do fabricated components reproduce the qualification properties? 5) Can the alloy be welded in heavy section in shop and field? 6) Will the welds survive plant thermal cycles? 7) Is the alloy damage tolerant, and can it be inspected and repaired if needed?

\section{Results and Discussion}

1. Does the Alloy Meet Design Property Targets? The alloy $740 \mathrm{H}$ composition was derived from alloy 263, an established aerospace sheet material. The alloy design criteria included the assumption that a minimum of 1 was needed for creep strength, with a maximum of $20 \%$ to avoid strain-age cracking during welding. About $25 \% \mathrm{Cr}$ was considered necessary for steam oxidation resistance. The third criterion was to minimize refractory elements such as Mo, $\mathrm{W}$ and $\mathrm{Nb}$, since they were associated with accelerated corrosion by sulfur-rich coal ash [5]. The nominal compositions of alloys 263,740 and $740 \mathrm{H}$ are shown in Table I. 
Table I. Nominal compositions in weight percent of alloys 263,740 and $740 \mathrm{H}$

\begin{tabular}{|c|c|c|c|c|c|c|c|c|c|c|}
\hline Alloy & $\mathrm{C}$ & $\mathrm{Cr}$ & $\mathrm{Mo}$ & $\mathrm{Co}$ & $\mathrm{Al}$ & $\mathrm{Ti}$ & $\mathrm{Nb}$ & $\mathrm{Mn}$ & $\mathrm{Fe}$ & $\mathrm{Si}$ \\
\hline 263 & 0.06 & 20 & 6 & 20 & 0.4 & 2.2 & - & 0.3 & 0.5 & 0.15 \\
\hline 740 & 0.03 & 25 & 0.5 & 20 & 0.9 & 1,8 & 2 & 0.3 & 0.7 & 0.5 \\
\hline $740 \mathrm{H}$ & 0.03 & 25 & 0.5 & 20 & 1.35 & 1.35 & 1.5 & 0.3 & 0.7 & 0.15 \\
\hline
\end{tabular}

The initial work on alloy 740 defined a heat treatment consisting of solution treatment at $1250^{\circ} \mathrm{C} / \mathrm{WQ}$ followed by age-hardening $4-16 \mathrm{~h}$ at $800^{\circ} \mathrm{C} / \mathrm{AC}$. This treatment produces a fine dispersion of scattered $\mathrm{MC}$ and a grain boundary network of $\mathrm{M}_{23} \mathrm{C}_{6}$. This microstructure was studied in detail by Evans [6] and Xie [7] who characterized its morphology and stability. It was observed that during long-time exposure at planned USA AUSC operating temperatures the alloy was prone to formation of acicular $\eta$-phase and globular G-phase. While Shingledecker [8] showed that $\eta$ does not affect creep strength, it was correlated with a loss of impact strength. Subsequently, the composition of 740 was modified, based on Thermo-Calc predictions, by ad usting $1 \mathrm{Ti}$ and $\mathrm{b}$ to stabili $\mathrm{e}$. Simultaneously, $\mathrm{Si}$ and $\mathrm{Nb}$ were lowered to reduce the liquidus-solidus range to improve heavy section weldability. The optimized alloy was introduced by Baker [9].

The creep rupture curves generated to date are shown in Figure 1. This data set includes data generated at Oak Ridge National Lab by the USA Consortium supplemented with Special Metals Corporation (SMC) internally generated data. Tests now running will extend this data set to beyond $100,000 \mathrm{~h}$. No significant difference was observed in the creep strength of 740 and $740 \mathrm{H}$. Figure 2 shows the ASME Code allowable design stress for $740 / 740 \mathrm{H}$ compared with several other code approved boiler materials. These data demonstrate that $740 \mathrm{H}$ does possess the required creep-rupture strength.

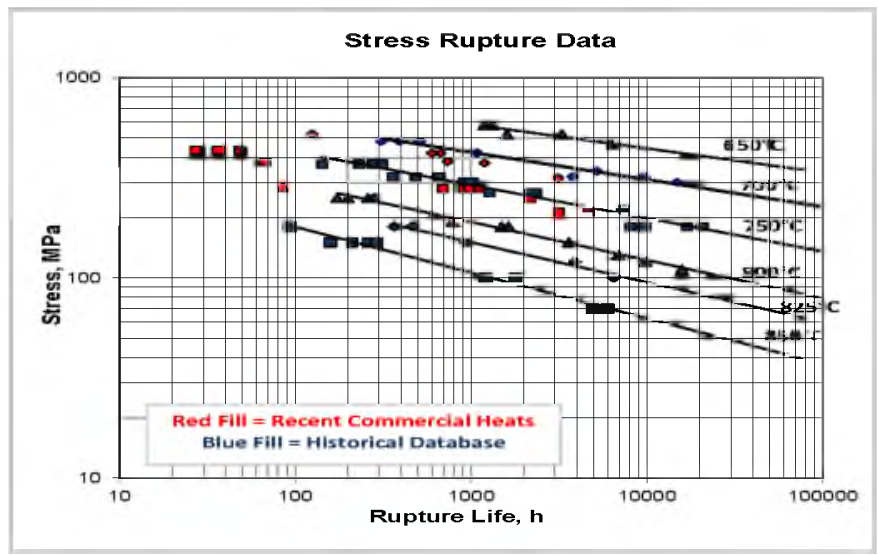

Figure 1. Composite creep-rupture data for $740 / 740 \mathrm{H}$, Oak Ridge and SMC data. 


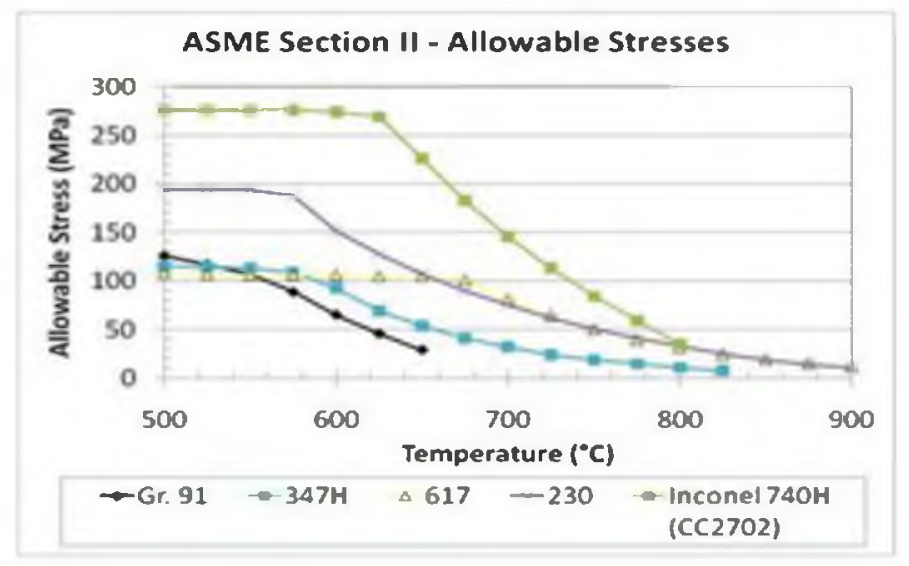

Figure 2. ASME Section 1 allowable stress values for code case 2702 (740/740H) [10].

Hot corrosion properties are more difficult to assess because they are highly dependent on boiler firing conditions, fuel impurities, de-slagging practices, operating temperature, etc. Several assessments of oxidation resistance for the steam-side of the boiler tube have been made. It was concluded that nickel alloys such as $740 \mathrm{H}$ that have more than $20 \% \mathrm{Cr}$ are suitable for use in AUSC plants [11]. A recent study illustrates the excellent fire-side hot corrosion properties of $740 \mathrm{H}$. In this case, $1000 \mathrm{~h}$ exposures were performed in a crucible with a mixture designed to simulate a common Chinese coal ash [12]. The $740 \mathrm{H}$ showed negligible attack in both base and weld metal compared with alloys 263 and 617, Fig. 3. This difference reflects the critical role of Mo in accelerating the onset of slag fluxing attack. It should be noted that no nickel-base alloy is fully immune to this form of hot corrosion and Natesan has postulated an incubation period following which all alloys are affected to some degree [13]. The results in simulated coal ash are generally supported by observations of direct exposure in plant trials [14]. Given the variability of process conditions, it can be concluded that alloy $740 \mathrm{H}$ has a high degree of corrosion resistance under AUSC boiler conditions, but it should be tested under the specific conditions of the plant under design to define corrosion allowances.

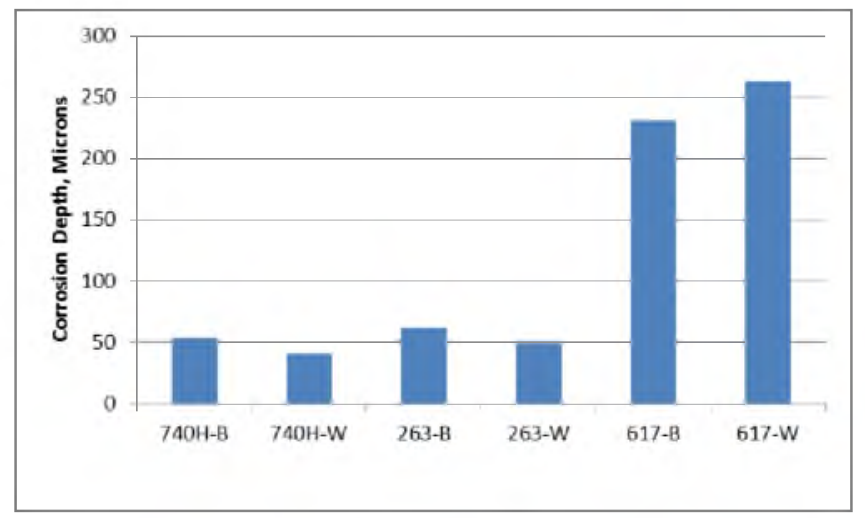

Figure 3. Corrosion pit depth for base metal (B) and weld metal (W) samples exposed 10,000 h in simulated coal ash [12].

2. Is the microstructure stable for the design life of a commercial power plant? This issue has already been introduced in the discussion of the evolution of 740 to $740 \mathrm{H}$. The loss of impact toughness during long time exposure of 740 was of concern to some AUSC designers. To evaluate the microstructural stability of $740 \mathrm{H}$, material obtained from tube and pipe was exposed 
stress-free for times up to $10,000 \mathrm{~h}$ at $700^{\circ} \mathrm{C}, 750^{\circ} \mathrm{C}$ and $800^{\circ} \mathrm{C}$. Longitudinal Charpy V-notch impact tests were conducted and the microstructure was analyzed in detail. The results of this investigation that were previously reported [15-16], are summarized below.

The microstructure of material as heat treated and material exposed for $5,000 \mathrm{~h}$ at the temperatures mentioned previously are shown in Fig $4 \mathrm{a}-4 \mathrm{~d}$. The series of SE micrographs show the progressi e growth and changing olum e fraction of . ot e that it continues to maintain a generally cubic morphology. arger chunky decorate the grain boundaries. Much of the remaining grain boundary area is covered by $\mathrm{M}_{23} \mathrm{C}_{6}$ carbides. Detailed phase identification was performed by Xie [16]. No evidence of $\eta$ or $\mathrm{G}$ phases was found. Sigma phase is predicted by Thermo-Calc to form at $650^{\circ} \mathrm{C}$ in this alloy at very long exposure times, but to date it has not been reported. Similar microstructures were observed after creep deformation shown in Fig $5 \mathrm{a}$ and $5 b$.

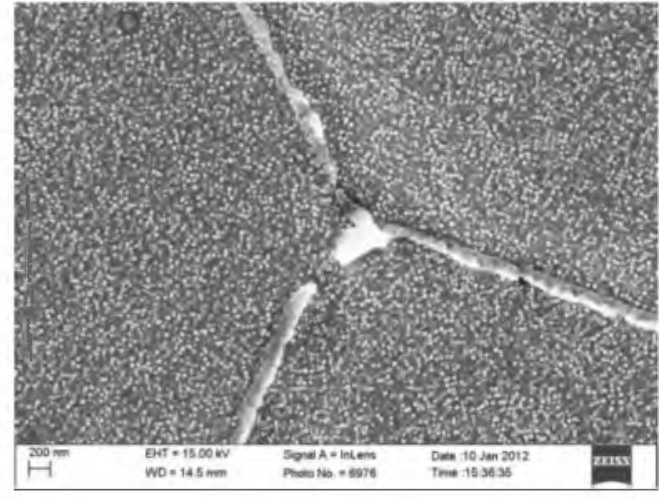

a)

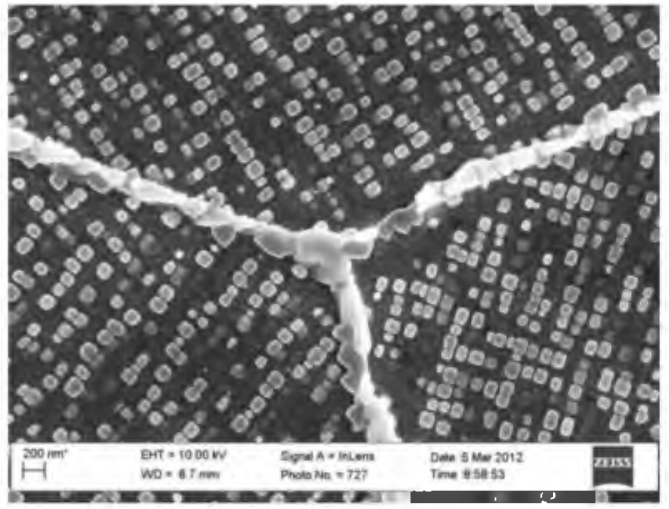

c)

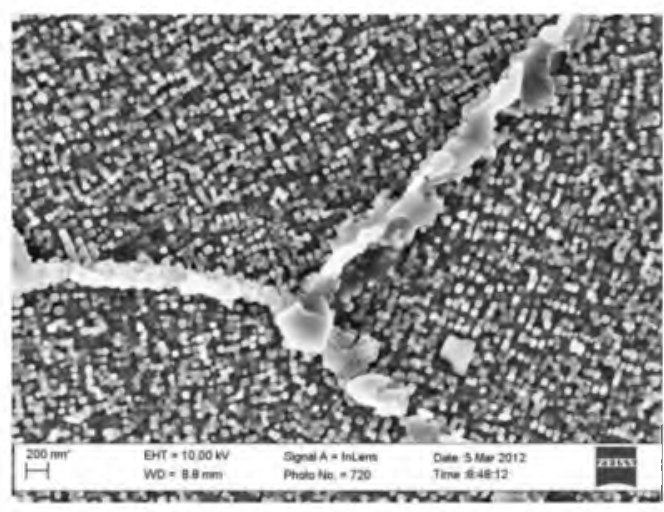

b)

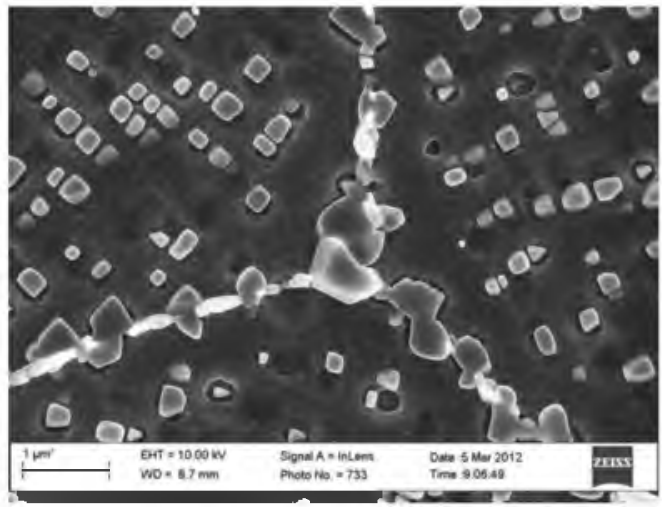

d)

Figure 4. Alloy $740 \mathrm{H}$ microstructure a) Solution annealed + aged, and after exposure for 5,000 h at b) $700^{\circ} \mathrm{C}$, c) $750^{\circ} \mathrm{C}$ and d) $800^{\circ} \mathrm{C}$ 


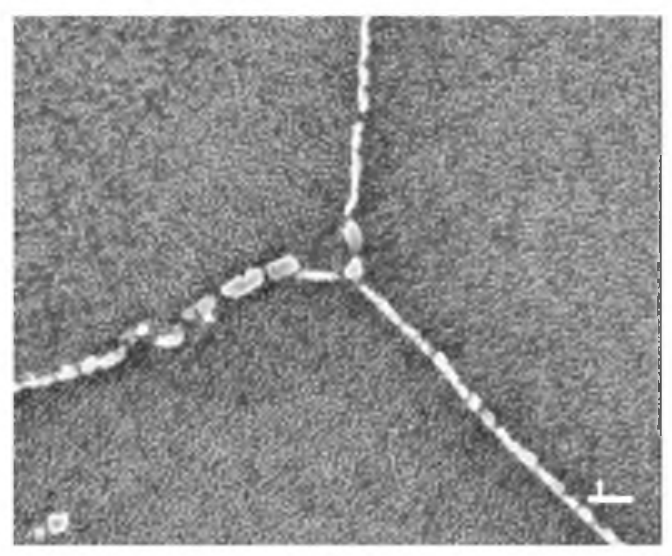

a)

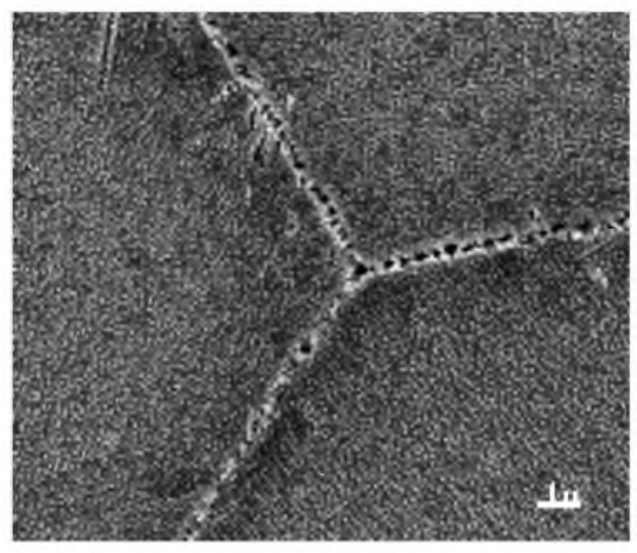

b)

Figure 5. Microstructure of creep specimen: a) low-stress shoulder, b) gauge section tested at $750^{\circ} \mathrm{C}, 1087.4 \mathrm{~h}, 280 \mathrm{MPa}$. The length standard is $1 \mu \mathrm{m}$.

The impact toughness was determined on both tube and pipe samples. The results are shown in Fig $6 \mathrm{a}$ and $6 \mathrm{~b}$. Toughness drops off during the first thousand hours, attributed to precipitation of additional and the formation of a thicker grain boundary carbide network; thereafter it levels off. These results taken with the microstructure observations show that $740 \mathrm{H}$ does have sufficient stability to serve in AUSC systems.

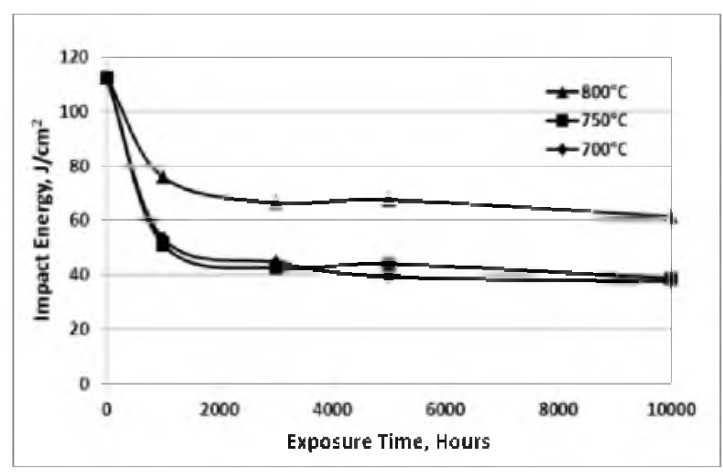

a)

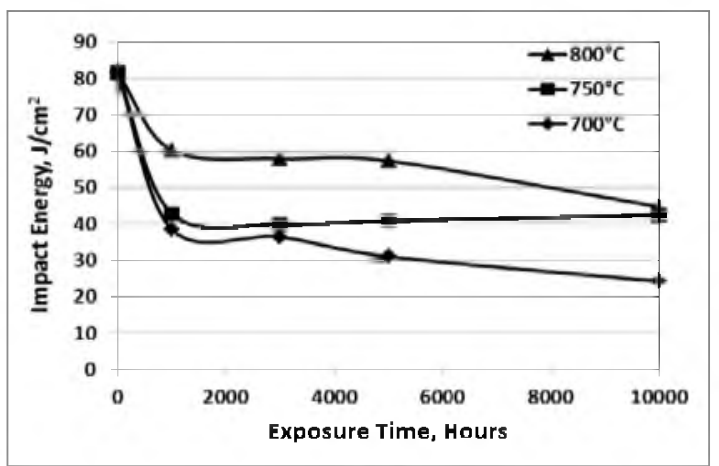

b)

Figure 6. Impact test results on a) tube and b) pipe materials exposed at various temperatures.

3. Can the alloy be made in the component sizes and configurations required? In the early stages of the AUSC program, superalloys were considered necessary only for superheater tubing that could be manufactured from small VIM/ESR ingots used for conventional aerospace applications. The first $50 \mathrm{~mm}$ OD $\times 10 \mathrm{~mm}$ W tubing was made under the Thermie program. This tubing was made by extruding billet cut from forged bar to tube shell and cold working to size using multiple pilger and anneal cycles. This tube process is similar to that used for other "hard" alloys such as 6 and 71. However, in the USA AUSC project with its planned higher operating temperature, superalloys would be needed for the much larger steam transfer pipes and associated connections. It was determined that solid solution alloys such as alloy 617 would be uneconomical because of the excessively heavy wall required for these lower strength materials [17], and that age-hardened alloys would be required. These structures are extremely large; some steel reheater pipes in current boiler designs are $1000 \mathrm{~mm}$ OD with $100 \mathrm{~mm}$ wall. Pipes of 
this size will require ingots on a size scale never previously made with strengthened alloys. The first demonstration heavy-wall superalloy pipe was extruded from alloy 263 in 2002 at WymanGordon Scotland. Although this relatively short pipe was made from a conventional size ingot, it demonstrated manufacturing feasibility of making heavy wall pipe [18]. Subsequently a larger pipe of alloy $740 \mathrm{H}$ was extruded at Wyman-Gordon Houston [19]. This $378 \mathrm{~mm}$ OD x $88 \mathrm{~mm} \mathrm{~W}$ $\mathrm{x} 10.5 \mathrm{~m} \mathrm{~L}$ pipe is shown in Fig 7. A $762 \mathrm{~mm}$ diameter, $7570 \mathrm{~kg}$ VIM/VAR ingot was used for this extrusion. VAR was selected in this case to minimize the risk of melt segregation. This is where the lessons of the alloy 706 development program came into play, as careful thermal profile management was necessary to prevent stress cracking. Excellent chemistry uniformity and microstructure was obtained. The detail for this work has been reported previously [20]. Based on this trial it was projected that a pipe as large as $750 \mathrm{~mm}$ diameter could be extruded on the Wyman-Gordon press.

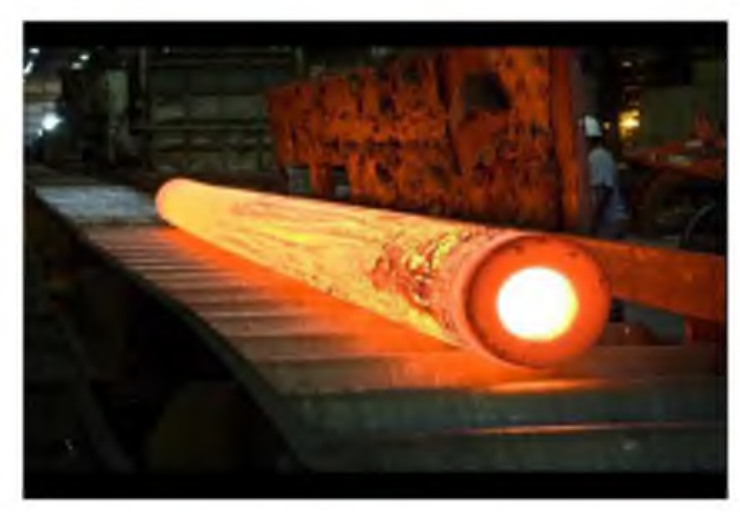

Figure 7. As-extruded alloy $740 \mathrm{H}$ header pipe [19].

An AUSC plant will require other product configurations besides straight length tubes and pipes. Several fabricators have demonstrated the ability to make bends in boiler tube. These bends are normally done cold with the material in the solution annealed condition. Alloy $740 \mathrm{H}$ has yield strength of $350 \mathrm{MPa}$ in the solution annealed condition with $55 \%$ elongation and hence can be formed on conventional cold tube bending equipment. Because the ASME code limits residual cold work prior to aging to $5 \%$, these bends must then be re-solution annealed and aged. Shingledecker has done a detailed study of the effect of cold work on the creep properties of bends [21]. His work showed that when the cold strain exceeded $5 \%$, the creep properties were reduced. This was attributed to vacancy formation leading to enhanced creep cavitation.

Heavy-wall header pipes are too large to cold bend and hence require hot forming. Short elbows may be forged, but large radius return bends must be made by induction bending. This process involves passing an induction coil incrementally along the pipe while simultaneously applying a slow bending moment. Material from a $324 \mathrm{~mm}$ pipe has been applied to make two trial bends The results and microstructure and property evaluation will be reported at a future date.

Various forged components will be required for an AUSC plant. Some are relatively small, such as flanges, saddles and weldolets. An example hammer forged flange that was recently made is shown in Fig. 8. Alloy $740 \mathrm{H}$ has relatively low flow stress compared with alloys such as 617 ( $75 \%$ over a wide range of temperature, strain and strain rate) and excellent hot ductility. Small parts can be cooled relatively quickly, so properties are expected to be similar to tubular products. However, rapid cooling is not possible for massive wyes (Y) and tees (T) which may be machined from block forgings. A calculated continuous cooling-transformation diagram for 
alloy $740 \mathrm{H}$ is shown in Fig 9. This diagram indicates significant hardening will occur even during water quenching. For example an air-cooled $450 \mathrm{~mm}$ billet bar had a hardness of Rc 36 compared with a fully solution treated tube hardness of $\mathrm{Rb} 90$. For large parts that must be machined, a spheroidizing treatment at $900^{\circ} \mathrm{C}$ will bring the hardness down to about $\mathrm{Rc} 24$. The effect of this auto-aging, which results in a bimodal size distribution, on final heat-treated properties has not been assessed.

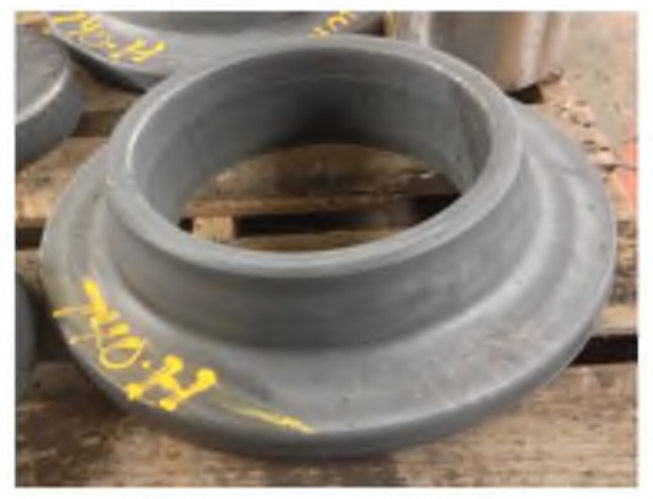

Figure 8. Hammer forged flange preform.

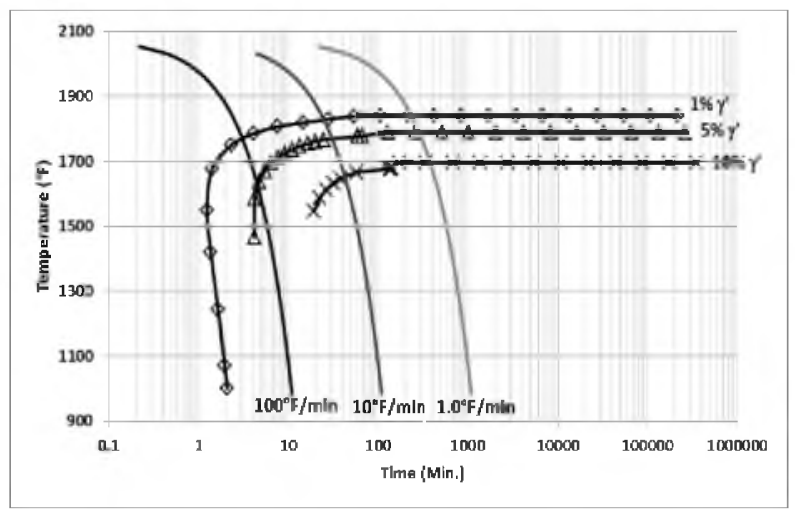

Figure 9. Calculated continuous cooling diagram for alloy $740 \mathrm{H}$ from JMatPro.

4. Do fabricated components reproduce the qualification properties? It is not uncommon for commercially produced material and especially complex forgings to have different properties than laboratory or pilot scale products used for material qualification. There are many reasons for this and the concern is well recogni ed; hence the need to demonstrate a new alloy's capability under typical manufacturing conditions. The technological development of superalloys for AUSC applications is currently in this phase.

Since boiler tube is solution annealed after cold working, the properties are not expected to be strongly affected by cold working methods (pilger, draw, roll form), but annealing processes can have a strong infuence. ue to rapid cooling precipitation is suppressed and hence annealed tube will be soft and ductile. Commercially, batch anneal and continuous anneal are widely used. Heating, equilibration, and cooling for these processes are dramatically different. In the case of alloy $740 \mathrm{H}$ both methods have been used successfully. The tensile properties at room temperature of selected tube production trials are shown in Table II. Table definitions: $0.2 \%$ offset yield strength (YS), tensile strength (TS), elongation (El) and grain size (GS). 
Table II. Room temperature tensile properties of $740 / 740 \mathrm{H}$ tube, pipe, and bar.

\begin{tabular}{|c|c|c|c|c|c|}
\hline & Size, $\mathrm{mm}$ & $\mathrm{YS}, \mathrm{MPa}$ & $\mathrm{TS}, \mathrm{MPa}$ & El $\%$ & GS \\
\hline ASME CC 2702 Min & NA & 620 & 1035 & 20 & NA \\
\hline Tube -740 & 50 OD $\times 10 \mathrm{~W}$ & 747 & 1172 & 37.5 & ND \\
\hline \multirow[t]{6}{*}{ Tube $-740 \mathrm{H}$} & 50 OD $\times 8 \mathrm{~W}$ & 716 & 1145 & 35.0 & 3.5 \\
\hline & & 735 & 1146 & 37.0 & \\
\hline & & 728 & 1163 & 36.0 & 3.5 \\
\hline & & 728 & 1160 & 36.5 & \\
\hline & & 836 & 1206 & 34.1 & 4 \\
\hline & & 855 & 1222 & 36.5 & \\
\hline \multirow[t]{6}{*}{ Pipe - 740H } & 378 OD $\times 88 \mathrm{~W}$ & 725 & 1084 & 31.9 & 2 \\
\hline & & 705 & 1074 & 31.4 & \\
\hline & & 737 & 1109 & 31.5 & 0 \\
\hline & & 746 & 1107 & 32.4 & \\
\hline & 324 OD $\times 22.5 \mathrm{~W}$ & 814 & 1158 & 31.8 & 5 \\
\hline & & 764 & 1086 & 31.9 & \\
\hline Bar -740 & $75 \mathrm{D}$ & 736 & 1147 & 36.5 & ND \\
\hline
\end{tabular}

Commercially produced pipe is generally extruded, batch annealed and aged. The heavier wall translates to reduced cooling rate and in the case of alloy $740 \mathrm{H}$ some auto-aging and hence higher hardness and reduced cold formability. The grain size generated during extrusion is inherited and difficult to change. Accordingly, pipe will tend to have a coarser grain size than tube. The elevated temperature tensile and creep-rupture results of pipe extrusions are shown in Table III and Fig. 10.

Table III. Elevated temperature tensile properties of $740 / 740 \mathrm{H}$ tube, pipe, and bar.

\begin{tabular}{|l|c|c|c|c|c|}
\hline & Size, mm & Temp, ${ }^{\circ} \mathrm{C}$ & YS, MPa & TS, MPa & EI \% \\
\hline ASME CC 2702 Min & NA & & NA & NA & NA \\
\hline Tube -740 & 50 OD x 10 W & 650 & 626 & 976 & 26.5 \\
\hline & & 700 & 670 & 932 & 18.5 \\
\hline & & 750 & 649 & 836 & 15 \\
\hline Tube -740H & 50 OD x 8 W & 650 & 604 & 964 & 28.5 \\
\hline & & 650 & 615 & 936 & 25.5 \\
\hline & & 700 & 626 & 903 & 17 \\
\hline & & 700 & 648 & 908 & 15.5 \\
\hline & & 750 & 610 & 802 & 13 \\
\hline & & 750 & 610 & 785 & 12 \\
\hline Pipe $-740 \mathrm{H}$ & 378 OD x 88 W & 650 & 600 & 920 & 29.8 \\
\hline & & 700 & 572 & 890 & 25.9 \\
\hline & & 750 & 573 & 799 & 22.5 \\
\hline & 324 OD x 22.5 W & 650 & 609 & 883 & 28.9 \\
\hline & & 650 & 683 & 992 & 24.5 \\
\hline
\end{tabular}




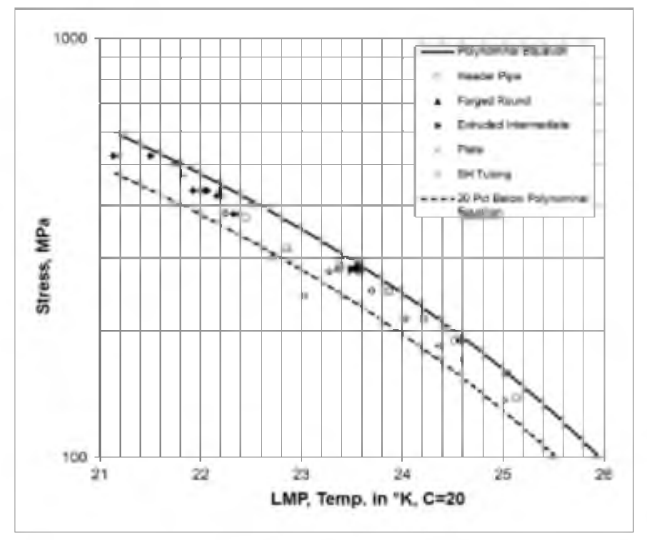

Figure 10. Creep-rupture properties of tube and pipe presented in Larson-Miller format. Solid line is polynomial fit of data submitted for the ASME code case. The dotted line is minus $20 \%$ of the polynomial stress.

5. Can the alloy be welded in heavy section in the shop and in the field? The initial welding studies on precursor alloy 740 showed that it could be readily welded by GTAW and GMAW with good operability, tensile and bend properties. Sucessful girth welds were made on boiler tubes [22,23]; however extensive microfissuring was experienced in restrained heavy section welds needed for steam transfer pipe. The redefined alloy $740 \mathrm{H}$ with its reduced liquidus-solvus range was shown to have excellent resistance to liquation cracking while retaining the operability characteristics of the original alloy [24,25]. Process parameters were optimised on $75 \mathrm{~mm}$ thick plates. They were then used to make circumferential welds on the $378 \mathrm{~mm}$ OD x $88 \mathrm{~mm} \mathrm{~W}$ pipe described previously. These welds were made using a hot-wire narrow-groove GTAW process with fixed torch and rotating work piece. Argon-25\% He was used as the shielding gas and used a matching alloy $740 \mathrm{H}$ filler wire composition. Welds were made with 5, 2 and 1 degree bevels. A cross-section of a weld with 1 degree bevel is shown in Figure 11. Note that the entire weld of 33 passes is one bead wide.

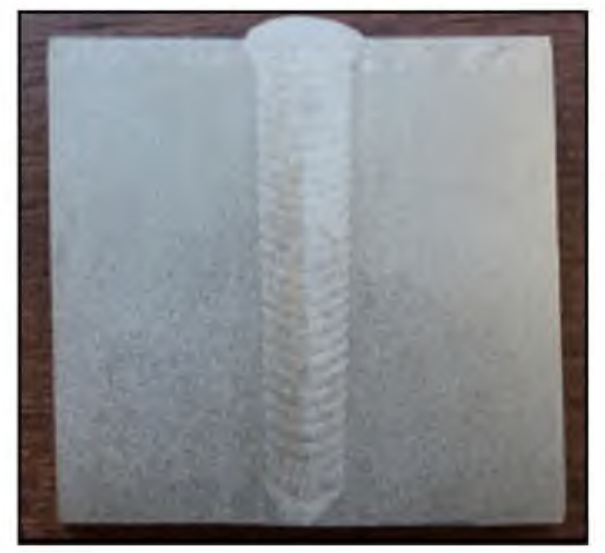

Figure 11. HW-GTAW weld in $75 \mathrm{~mm}$ wall $740 \mathrm{H}$ pipe

The full welded pipe section was aged per ASME code requirement for $5 \mathrm{~h}$ at $800^{\circ} \mathrm{C}$ using a ceramic tile heating blanket. This method is commonly used for post weld heat treatment (PWHT) of field welds. The weld was initially evaluated for ASME Section IX qualification. Room temperature tensile properties and code requirements are shown in Table IV. The 2T side 
bends passed. No fissures or weld cracking was detected with radiography or microscopic examination.

Table IV. Cross-weld tensile properties for pipe weld in $740 \mathrm{H}$

\begin{tabular}{|c|c|c|c|c|}
\hline $\begin{array}{c}\text { Sample } \\
\text { Location }\end{array}$ & YS, MPa & TS, MPa & El, \% & $\begin{array}{c}\text { Fracture } \\
\text { Location }\end{array}$ \\
\hline OD & 815 & 1135 & 21.3 & W \\
\hline OD & 803 & 1123 & 21.2 & W \\
\hline Mid Wall & 763 & 1098 & 24.6 & B \\
\hline Mid Wall & 758 & 1089 & 20.6 & B \\
\hline ID & 750 & 1081 & 21.4 & B \\
\hline ID & 756 & 1087 & 24.4 & B \\
\hline ASME Reqt. & 620 & 1035 & 20 & \\
\hline
\end{tabular}

Once it was determined that sound welds could be made in heavy-wall pipe, a full scale header mock-up was fabricated. This is a short replica of a much longer pipe in a power plant in which hundreds of boiler tubes are attached to nipples inserted in the main steam transfer pipe. In this case the nipples were GTAW welded on the inside with a special rotary torch. The external welds were manual GTAW. This prototype header section is shown in Fig. 12. Following fabrication of the mock header pipe, similar welds have been successfully made by shop welders using production equipment.

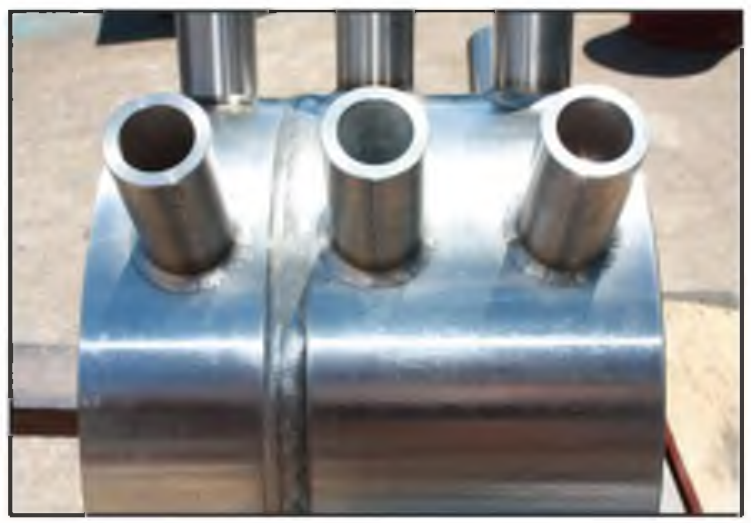

Figure 12. Simulated header pipe made from alloy $740 \mathrm{H}$.

6. Will the alloy welds survive power plant thermal cycles? Extensive cross-weld creep testing has been conducted at Oak Ridge National Lab and results reported by Santella [26] and analyzed by Shingledecker [10]. It has been shown that the creep strength of $740 \mathrm{H}$ welds is $30 \%$ lower than that of the base metal. Based on this data ASME has assigned a reduction factor of 0.7 for welded joints where transverse stresses are present. This is of primary concern for longitudinal welds, a configuration not expected to be used in AUSC design. Due to this reduced strength, creep strain can be expected to be spread out over the entire weld bead. This may actually be beneficial because alloy $740 \mathrm{H}$ weldments do not have a narrow constrained heataffected zone where cracking often occurs in heat-resisting alloys.

Strain aging effects in precipitation-hardened nickel-base alloys are often associated with stress relief and stress relaxation cracking of welds. The former may occur during heating for postweld heat treatment. Waspaloy is an alloy that is particularly prone to this mode of cracking. 
Some studies have been performed on $740 \mathrm{H}$ using a Gleeble test [25]. These tests show that alloy $740 \mathrm{H}$ is similar to alloy 718 , an alloy generally considered not susceptible to stress relief cracking. It should also be noted that no cracking has been found by radiography or microstructural examination of any of the four pipe welds made to date.

Stress relaxation cracking is more insideous in that it occurs during service, sometimes after years of operation. It is thought to occur in highly restrained welds as the stresses slowly relax while precipitation occurs. It should be noted that about 3 additional precipitates in $740 \mathrm{H}$ during the first 1,000 hours of exposure at $700^{\circ} \mathrm{C}$ after initial aging at $800^{\circ} \mathrm{C}$. This additional precipitation could cause strain aging. There are a variety of tests for stress relaxation cracking, but none of them provide an unambiguous prediction of cracking tendency. Special Metals is using a circular patch test that is commonly called a Borland test [29]. In this test $37 \mathrm{~mm}$ plate with a machined circular U-groove was securely welded to a strongback. The groove was filled with ten passes using a manual GTAW process. The plate was given an $800^{\circ} \mathrm{C}$ PWHT and then exposed at $700^{\circ} \mathrm{C}$. At the time of this writing, the test specimen had been exposed for $3,000 \mathrm{~h}$ and the test is continuing. It has been periodically removed from the furnace and examined by radiography to check for voids and cracks. It is planned to continue the test until it cracks or $10,000 \mathrm{~h}$, after which it will be cut up for metallographic examination. It should be noted that this severe test does not ensure that cracking will not occur in service and hence the upcoming in-plant testing experience will be critical for characterizing the behavior of the alloy.

7. Is the alloy damage tolerant and if damaged can it be inspected and repaired? Damage tolerance is of increasing concern to the electrical utility industry because high performance materials tend to be less ductile and hence less forgi i ng to microstructural "damage" such as creep voids. The actual loading mechanism in a boiler is not simple uniaxial tension; areas of biaxial or triaxial tension will be present along with fatigue loading and sub-surface oxide formation. All of these conditions will interact with an evolving microstructure. Currently there is no universal way to measure damage tolerance, however, this will be a prime area of investigation for the in-plant test loops now being designed. Material procurement of various candidate alloys including $740 \mathrm{H}$ is underway in China and Japan for installment in 2014. Similar facilities are under consideration in the U.S and India.

\section{Summary}

It has been shown that an age-hardenable nickel-base alloy must meet challenging and diverse criteria for service in AUSC power plants. These criteria extend beyond the primary alloy design properties of creep strength and corrosion resistance; they also include microstructure stability, weldability, damage tolerance, and the ability to manufacture a range of sizes of tube, pipe and fittings with acceptable properties. Alloy $740 \mathrm{H}$ is the first of a generation of new superalloys optimized for such uses in these advanced power plants, and the first to receive ASME Boiler Code approval. Extensive evaluation of the alloy has been conducted in laboratories around the world. The alloy composition was adjusted to provide for microstructure stability and heavy section weldability. A few issues remain such as the relatively low weld creep strength; however the alloy has shown sufficient promise to enter the critical prototype testing phase. Testing under actual operating conditions will then answer the question of whether age-hardened superalloys are ready for power plant service. 
The experience in the development of alloy $740 \mathrm{H}$ has shown that the cost and difficulty of qualifying a new alloy for a new process steadily escalates as the product matures. While this is not a new concept, it is often overlooked in project planning. In particular, providing a full range of mill and fabricated products for pilot testing programs is challenging because the relatively small quantities needed are not compatible with desired manufacturing volumes and efficiencies. If product shortcomings are identified at this stage, they can be especially costly to rectify. In the example discussed in this paper, some shortcomings of the alloy are apparent, but with the investment in data collection and analysis for qualification, they will have to be accommodated until the AUSC process itself becomes established.

\section{Acknowledgements}

The authors are indebted to the USA AUSC Consortium that has conducted extensive evaluation of $740 \mathrm{H}$ and generated much of the data provided to ASME to support Code Case 2702 and in particular to Babcock and Wilcox in Barberton $\mathrm{OH}$, that graciously provided access to their unique welding facilities.

\section{References}

1. J.J. deBarbadillo and S.K. a nnan; "1lo y 71 for Oilfield pplica tions" Proceedings of the $7^{\text {th }}$ International Symposium on Superalloys 718, 625 and Various Derivatives, E.A. Ott et al ed. TMS, 2010, pages 579-593.

2. P.J. Shilke J. Pepe and R. Schwant; "llo y 706 etallurgy and Turbine Wheel ppli cation" Superalloys 718, 625, 706 and Various Derivatives, ed. E.A. Loria, TMS 1994, 1-12.

3. K. ic hol "Status of d a nced ltra -supercritical Coal-fired Power Plant" IE Clean Coal Centre, London, UK, 2013.

4. "Case 70 Seamless i-25Cr-0C o a terial Section 1" Cases of the ASME Boiler and Pressure Vessel Code, BPV-Supp. 7 2011, American Society of Mechanical Engineers.

5. B.A. Baker, " e w llo y Designed for Superheater Tubing in Coal-Fired Ultrasupercritical Boilers" Superalloys 718,625,706 and Derivatives 2005, E. A. Loria ed. TMS, 2005, 601-611.

6. N.D. Evans, P.J. Masiasz, R.W. Swindeman and G.D. Smith "icr ostructure and Phase Stability of ICO E alloy 70 ur ing Creep" Scripta Materialia, Vol. 51, 2004, 503-507.

7. S. Zhao, J. Dong, X. Xie. G. . Smith and S.J. Patel; "Thermal Stability Study on a e w i Cr-Co-Mo-Nb-Ti- 1 Superalloy", Superalloys 2004, Ed. K.A.Green, et al, TMS, 2004, 6372.

8. J.P. Shingledecker . and G. . Pharr "The Role of Eta Phase Formation on Creep Strength and Ductility of INCONEL Alloy 740 at $1023 \mathrm{~K}\left(750^{\circ} \mathrm{C}\right)$, Metallurgical Transactions $A$, 2012, Vol. 43, 1902-1910.

9. B.A. Baker and R. . Gollihue "Optimi ation of ICO E alloy 740 for Advanced Ultra Supercritical Boilers" Proceedings, $6^{\text {th }}$ International Conference on Advances in Materials Technology for Fossil Power Plants, EPRI, Santa Fe, NM, 2010, 96-109.

10. Shingledecker J.P. "Creep-rupture Performance of INCONEL Alloy 740 and Welds" Proceedings: $7^{\text {th }}$ Int. Conf on Advances in Mat. Tech for Fossil Power Plants, EPRI, Waikaloa HA, 2013, 230-241.

11. J.M. Sarver and J. Tan osh " $n$ Evaluation of the Steamside Oxidation of USC Materials at $650^{\circ} \mathrm{C}$ and $800^{\circ} \mathrm{C}$ "Advances in Materials Technology for Fossil Plants, Viswanathan ed. ASM International, 2005, 192-212. 
12. B.A. Baker, R.D. Gollihue, J.J. de Barbadillo, S.J. Patel and D. Maitra, Manufacturing Demonstration of Inconel llo y 70 for SC Boilers", Proceedings: $7^{\text {th }}$ Int. Conf on Advances in Material Technology for Fossil Power Plants, EPRI, Waikaloa, HA, 2013, $215-$ 229.

13. K. Natesan Z. Zeng and . Rink; "a terials Performance of Structural llo ys in Simulated Oxy-fuelEnvironments, Proceedings of $25^{\text {th }}$ Anmual Conference on Fossil Energy Materials, DOE-NETL, Pittsburgh, May 2011.

14. M.S. Gagliano . a ck and G. Stanko; "Fireside Corrosion Resistance of Proposed SC Superheater and Reheater a terials" Proceedings of $34^{\text {th }}$ International Technical conference on Clean Coal and Fuel Systems, Coal Technology Assoc., Clearwater, FL, May 2009

15. J.J. de Barbadillo,, B.A. Baker and X. Xie "ic rostructure Stability of lloy 70 and its Effect on a terial Properties" Proceedings of the ASME Symposium on Elevated Temperature Application of Materials for Fossil, Nuclear and Petrochemical Industries, ASME, Seattle WA, March 25-27, 2014, to be published.

16. X. Xie, S. McCoy, and J.J. de Barbadillo, "High Temperature Structure Stability Study on Ni-Base Superalloys for $700^{\circ} \mathrm{C}$ A-USC Fossil Power Plants After Long Time Aging and Creep Tests", submitted to $10^{\text {th }}$ Liege Conference on Materials for Advanced Power Engineering, Sept 14-17, 2014.

17. J.P. Shingledecker et al “.S. Program on d a nced Supercritical Power Plant a terials Advanced Ultrasupercritical Coal-fired Power Plants, Vienna, Austria, September 19-20, 2012.

18. P. Barnard "Characteri ation of imoni c 63 for Thick Section Components for -USC Boiler pplica tions" Presented at Global Advanced Fossil-Gen Summit 2011, Asian Coalition for Climate and Energy, Shanghai, China, Dec 6-7, 2011.

19. L. Klingensmith “ e e lopment of Extruded ea y Wall arge ia meter ic kel-Base Alloy Piping for A-SC Power Plants" Global Advanced Fossil-Gen Summit 2011, Asian Coalition for Climate and Energy, Shanghai, China, Dec 6-7, 2011, 272-298.

20. J.J. de Barbadillo, S.J. Patel, B.A. Baker and R.D. Gollihue, " i ckel-Base Superalloys for d a nced Supercritical Power Plants" Global Advanced Fossil-Gen Summit 2011, Asian Coalition for Climate and Energy, Shanghai, China, Dec 6-7, 2011, 244-272.

21. J.P. Shingledecker, and G. . Pharr; "Testing and na lysis of Full-Scale Creep-Rupture Experiments on Inconel 1lo y 70 Cold Formed Tubing" Journal of Materials Engineering and Performance, Vol 22, Issue 2, 2013, 454-462.

22. J.M. Sanders, J.E. Ramire and B. . Baker "Weldability In e stigation of Inconel Alloy 740 for Itra Supercritical Boiler pplica tions" Advances in Materials Technology for Fossil Power Plants 2007: Proceedings of the Fifth International Conference, ASM International, March 2008, 818-829.

23. J.M. Sanders B. Bake r J. . Siefert and R. . Gollihue "Elimination of Fissures in Thick Section Inconel alloy 70 Welds" Proceedings of $34^{\text {th }}$ Anmual International Technical Conference on Clean Coal and Fuel Systems, Coal Technology Association,Clearwater FL, May 31, 2009.

24. J.A. Siefert J. J. . Tan osh and J.E. Ramire "Weldability of Inconel Alloy 70 " Proceedings of the Sixth International Conference in Advances in Materials Technology for Fossil Power Plants", Santa Fe, NM, Aug 31-Sep 3, 2010, 1045-1066.

25. B.A. Baker R. . Gollihue and J.J. deBarbadillo; "Fabrication and e at Treatment of Weld Joints in Inconel 1lo y 70 Superalloy Steam e ader Pipe and Superheater Tubing" Welding and Repair Technology for Power Plants, Tenth International EPRI Conference, Marco Island, FL, June 26-29, 2012. 
26. M. Santella J.P. Shingledecker and O. Barabash "Creep Rupture Testing of Inconel 740HWeldments, Presentation at TMS Annual Conference, San Diego, March 2, 2011.

27. J.C. Borland "Cracking Tests for sse ssing Weldability" British Welding Journal, Vol 7, $1960,508-512$. 